transition from the aesthetic to the ethical. But it is not at all clear that such a model can account for the movement from the ethical to the religious, since the qualitative transition to faith involves, among other things, the paradox of the forgiveness of sins. In fact, Ferreira offers no sustained analysis of the concept of grace in her book.

Despite these reservations, it must be stressed that Ferreira's study is deserving of high praise. The analysis of religious conversion developed there is not only compatible with key themes in Either/Or; it may well be right as an account of how such transitions occur. The main critical question I have raised, however, is whether such an analysis can finally be made to square with Climacus's notion of the leap, and the emphasis he places on conscious decision. Ferreira's interpretation will undoubtedly stimulate further discussion about these central ideas.

STEVEN M. EMMANUEL

Virginia Wesleyan College

The Disappearance of Time: Kurt Gödel and the Idealistic Tradition in Philosophy. PALle yourgrau. New York: Cambridge University Press, 1991. Pp. x, 182.

In his contribution to the Schilpp volume on Albert Einstein: Philosopher and Scientist, entitled "A Remark about the Relationship between Relativity Theory and Idealistic Philosophy," Kurt Gödel argues, in the tradition of McTaggart, Parmenides, and Kant, that time is ideal; an illusion that represents nothing in objective reality. But what is time? As Gödel conceives of it, time involves an objective lapse or flow. "The existence of an objective lapse of time [whose essence is that only the present really exists], however, means (or, at least, is equivalent to the fact) that reality consists of an infinity of layers of the 'now' which come into existence successively" (23-24). Thus, if (A-theoretic) time is real then there must be temporal becoming, "that successive time that unfolds into an open future" (128), which itself implies, as Richard Jeffrey puts it, that "[r]eality grows by accretion of facts: (23). Yet there appear to be numerous difficulties with the Atheoretic conception of time.

First, there is Gödel's argument from physics: Change implies A-time. If, however, Einstein's theory of relativity is true (and it is), and by implication, Gödel's R-universes with time travel are possible (and they are), then the A-theoretic conception of time is false, not only in the theoretically possible world in which time travel is possible, but in our world as well. Therefore, A-time and change are an illusion and unreal.

Second, there is the argument from metaphysics, an argument that originated with Parmenides: Reality is the changeless totality of all that is (tenselessly) the case. If, however, time is real, then the sum total of reality must change; it must increase (with the accretion of facts) as the nonexistent future becomes present. Thus, time is unreal. Then there is the argument from semantics, according to which the meaning of a sentence in which "now" occurs is compatible with its truth conditions being entirely tenseless. And finally, there is an argument from logic which purports to demonstrate that no formalism of tensed time, even the most sophisticated, such as R. Thomason's "Indeterminist Time and Truth-Value Gaps," Theoria 36 (1970): 264-81, is adequate to represent A-time. 
In this relatively short book, Palle Yourgrau attempts to tackle all of these difficulties and point the way to a solution to some of them. In the course of doing so he has many provocative and valuable points to make concerning such issues as the correct interpretation of Gödel's idealism (chapters 1-2); time travel and the Gödel universe (chap. 3); whether or not A-theoretic time is compatible with relativity theory (chap. 4); ${ }^{1}$ Frege's semantics (chap. 5); and the relations between time and potential and actual infinity, and time and the understanding of human existence (chap. 6).

Throughout The Disappearance of Time Yourgrau attempts to defend two main theses: (1) Gödel has shown that since objective "time" has a B-theoretic (tenseless) structure, time is not real. (2) Since our temporal intuitions and experiences imply time has an A-theoretic (tensed) structure, time is real. Yourgrau sums up these two themes when he says, "time seems at once to demand and to resist a reconciliation between its subjective, intuitive, manifestations and its appearance in the best models that have been offered to date to incorporate its peculiar being into the fabric of the objective world" (176). Within the confines of a brief review I cannot do justice to the many arguments Yourgrau uses in support of these important theses. Since, however, I do not believe he has established either of them, I want to indicate the directions I would develop to defend my assessment.

The B-theoretic view of time holds that all past, present and future events exist tenselessly in the network of earlier, later and simultaneity relations. According to Yourgrau and Gödel, this view spatializes time by eliminating genuine succession from the temporal. For if something's location in "time" has no effect on its existence, then the series of events in "time" is like a "platonic object whose members do not come into existence successively" (11) or a spatial object all of whose parts already exist, laid out "in bloc" (72). In either case, the "temporal mode of being" in which to exist is to be present, is lost (11).

The possibility of time travel in Gödel's R-universes allegedly supports this criticism of the B-theory for '[I]n such worlds one can, in effect, 'travel' in time in the same way we can not travel in space, and, in particular, though always heading into our causal future, we eventually arrive at our past or present" (20). If by travelling into our causal future we arrive at the past, a temporal loop or circle is formed in which one and the same event, for example, travelling in a time machine, may be later and earlier than the event of entering the time machine. However, if the terms of a series stand in symmetric relations, when we no longer have a temporal series with an intrinsic direction from earlier to later (42-53).

There are two assumptions underlying this argument. The first is that temporal relations are definable in terms of causal relations; that the order of causality is the order of time. The second is that temporal loops are possible because causal loops are possible, that is, an effect can precede its cause. Surprisingly, neither of these assumptions is examined in Yourgrau's discussion of time travel. D. H. Mellor, who accepts a version of the causal theory of (tenseless) time, rejects the possibility of backward causation (and hence time travel), but Yourgrau does not con-

1 For recent discussions of this issue see, Howard Stein, "On Relativity Theory and Openness of the Future," Philosophy of Science, 58, 2 (1991), pp. 147-67; and Quentin Smith, Language and Time (New York: Oxford University Press, 1993), chapter seven. 
sider Mellor's arguments. ${ }^{2}$ Moreover, a B-theoretician can admit all terms on the B-series are ontologically on a par, having tenseless existence at the particular clock times they do, and yet reject the view that temporal relations are definable in terms of causal relations, or are definable at all. As Yourgrau himself says, in the context of defending a Platonic view of the self, "[P]hysics is not ontology" (148).

Russell, (the early) C. D. Broad, myself and others have maintained that temporal relations are primitive and unanalyzable relations, and the difference between spatial and temporal relations is an irreducible qualitative difference. ${ }^{3} \mathrm{On}$ this view, we directly experience temporal relations between tenseless existents whenever, for example, we hear a tune in which one note precedes another. As Broad has said, "On these relations of before and after which we immediately recognize in certain objects of our experience all further knowledge of time is built." In short, a B-theorist can say of temporal relations what Yourgrau says of temporal becoming, namely, "the notion of nuns fluens, [if it is] to be made sense of at all, must be regarded as primitive, as sui generis" (29).

The B-theoretic structure of time does imply that all terms in the B-series exist tenselessly; there being no special property possessed by events that are present. However, the B-theory neither spatializes time nor takes away "genuine possibilities" and free will (46), unless one assumes A-theoretic conceptions of succession and the open future. What reasons are there, then, to believe time has an A-theoretic structure? Conversely, why does Yourgrau claim "[I]f, with Gödel, we maintain the ideality of time-that successive time that unfolds into an open futurewe abandon not only our overtly temporal intuitions..., but also certain otherwise clear, natural, and intuitive distinctions of a mathematical, as well as of a more general human significance"? (128)

Yourgrau appeals to our "direct experience" of time, "the phenomenon of lived time... [and] the human significance of the present moment" (127) in order to support that A-theoretic view. Thus, he claims, following Prior and others, that Btime cannot provide a plausible explanation of the presence of experience and our different attitudes toward past, present and future events, especially the fear of death (126-27, 150-51). Though these objections to B-time need to be answered, recent discussions of the issues (some of which Yourgrau can be faulted for not considering) have gone a long way toward answering them. ${ }^{5}$

2 See, D. H. Mellor, Real Time (New York: Cambridge University Press, 1981), pp. 160 87.

3 See, Bertrand Russell, "On the Experience of Time," The Monist, 25 (1915), pp. 212 33. C. D. Broad, "Time," in J. Hastings, ed., Enclyclopaedia of Religion and Ethics, vol. 12 (New York: Charles Scribner Sons, 1955), pp. 334-45. L. Nathan Oaklander, Temporal Relations and Temporal Becoming (Lanham, Maryland: University Press of America, 1984). J. M. Shorter, "The Reality of Time," Philosophia, 14, 1-2 (1984), pp. 321-39.

4 C. D. Broad, "Time," op. cit., p. 334.

5 Murray MacBeath, "Mellor's Emeritus Headache," in The New Theory of Time (hereafter $N T$ ), L. Nathan Oaklander and Quentin Smith, eds. (New Haven: Yale University Press, 1994), pp. 305-311. D. H. Mellor, "MacBeath's Soluble Aspirin," Ratio, 25, 1 (1983), pp. 89-92. L. Nathan Oaklander, "Thank Goodness It's Over," and "On the Experience of Tenseless Time," in $N T$, pp. 325-27 and 344-50. Clifford Williams, "The Phenomenology of B-Time," in NT, pp. 360-72. 
Yourgrau maintains that the mathematical distinction between the potential and the actual infinite implies time is A-theoretic. He says, "[A] quantity is potentially infinite if it increases without limit or if it goes on forever. With the latter formulation we see time enter the picture, and it must clearly be successive, forever incomplete A-theoretic time" (129). Maybe a potentially infinite series must be incomplete, but surprisingly (and paradoxically) it does not necessarily follow that A-time must be "forever incomplete." After all, it is only the contingent part of the future, i.e., chance events and human actions open to deliberation, that are open and not yet determinate. On the standard model of A-theoretic time, facts about the future that have determining causes are closed, being founded upon what already exists. Thus, if the physical universe is causally closed, and human beings (and actions open to deliberation) eventually cease to exist, then A-time would be closed and complete. (And even if the universe is always partially indeterminate there is still the puzzling question of how the partially open future can come into existence simultaneously with the partially closed future.)

Yourgrau aligns himself with Plato and Gödel who "view our embodied existence, in this world, as at best a confused and cloudy preparation for something more meaningful--in our postnatal nonexistence (i.e., nonexistence after death in this world)" (153). Furthermore, if the selfsame being changes from the state of existence to nonexistence (or the reverse), then, according to Yourgrau, A-theoretic time must be real (151-52). Although Yourgrau gives arguments to support this essentially Platonic view of the self, I remain skeptical.

Yourgrau's honest attempt to deal with the difficulties facing the A-theory is laudable. Nevertheless, when he suggests we pay too high a price if we adopt an idealist conception of time and abandon the A-theory, I demur. Indeed, I would suggest the price we have to pay to abandon the A-theory is well worth it.

\section{NATHAN OAKLANDER}

University of Michigan-Flint

Unnatural Doubts. MICHAEl Williams. Oxford: Blackwell, 1991. Pp. xxiii, 386.

This book is about a certain kind of external world skepticism and Williams's "diagnosis" of it. The author contends that there is no such thing as knowledge of the external world. What he means is that there is no such thing as knowledge of the external world as a kind of knowledge, considered as a whole, as an object of theory. Further, according to Williams, there is no genuine question how we can know anything about the world. It doesn't follow that Williams supports skepticism, which he sees as a pessimism. Rather, he claims that certain skeptical doubts, while understandable, are unintuitive and unnatural.

Williams's aim is to give what he calls a theoretical diagnosis of skepticism. He agrees with his skeptic that no satisfactory constructive response to skepticism is possible (pace Kant). Williams suggests, rather, that something is wrong with the way skeptical questions are asked and that we need a deep diagnosis of the sources of skepticism. He eschews any attempt to dissolve the problem of skepticism; rather he suggests that the way around the problem is to get the skeptic to take the responsibility of sharing some of the burden of theory (p. xxvii). Once a skeptic does this, Williams argues, she is committed to a very far reaching founda- 